\title{
An ultrasonic motion detector, with data on stare, restriction of movement, and startle*
}

\author{
JAMES M. DABBS, JR., and BRENDA J. CLOWER \\ Georgia State University, Atlanta, Georgia 30303
}

The ultrasonic motion detector can measure activity in free-ranging Ss; it may be useful in studies of arousal. This device records counts of activity per unit of time. Sixty Ss were run in three experiments to evaluate the convenience and usefulness of the technique.

Francis Galton (1885) suggested that measures of activity should be effective, unobtrusive, and usable in ordinary situations. Developments since Galton's time have been limited, and unobtrusive observation of activity today is complicated and tedious (Webb, Campbell, Schwartz, \& Sechrest, 1966, pp. 150-155).

Burglar alarm specialists have been more successful than psychologists in measuring activity unobtrusively. Their equipment meets Galton's criteria and, furthermore, is simple enough to be used by an ordinary citizen. Designed to signal the presence of movement, the equipment can be modified to monitor amount of movement. The resulting measure of overall activity may be useful in studying a number of individual or social processes.

Three experiments reported here were designed to test the research utility of an ultrasonic motion detector. The device was used to obtain measures and to produce experimental treatments. The experiments dealt with responses to being stared at, to restriction of movement, and to $a$ startle stimulus. These studies and other exploratory observations have helped clarify the utility and limitations of the equipment.

\section{METHOD AND RESULTS}

The motion detector was located in a $3 \times 3 \times 10$ in. box placed on a bookshelf a few feet from where $S$ was seated. A bookshelf partition shielded E's movements from the motion detector. The device transmitted a $35 \mathrm{kc}$ tone and monitored changing frequencies in the returning echos caused by the S's movements. Voltage changes representing movement actuated a relay located in another room. The relay closed repeatedly, at rates ranging up to about $20 / \mathrm{sec}$, as long as movement occurred. (Relay closures can be fed into an electromechanical counterprinter or into solid-state recording equipment.) Highest closure rates occurred when the movement was fast, close to, or directly toward or away from the motion detector (direction of

\footnotetext{
*This research was supported in part by U.S. Public Health Service Grant MH 20660. The authors wish to thank $R$. Chris Martin for providing the equipment and Ellie Harold for helping collect the data. Further information on the ultrasonic motion detector can be obtained from the authors or from R. Chris Martin. RCM Enterprises, 6600 Blue Parkway, Kansas City, Missouri 64129.
}

movement matters less when $S$ is farther away from the motion detector).

\section{Experiment 1: Staring \\ Ss were 10 male and 10 female undergraduate} psychology students. S sat at a small table with the motion detector beside and slightly in front of him. E (a female) sat at a desk about $7 \mathrm{ft}$ in front of and normally facing away from the $S$. E explained that $S$ would be required to estimate time under various conditions. No mention was made of the motion detector. A small signal lamp (turned off) was mounted on the table in front of $S$, and $E$ suggested that the task would be easier if $S$ spent most of the time looking at the lamp. Following this general introduction, $\mathrm{S}$ was required to estimate how much time had passed during three subsequent periods, each of which in fact lasted $5 \mathrm{~min}$. E faced away from $S$ during the first period; turned and watched $S$ continuously during the second, and faced away from $S$ again during the third. Electromechanical recording equipment was used, and activity counts were printed at $15-\mathrm{sec}$ intervals throughout the session.

There is currently some interest in the effects of staring upon behavior (cf. Ellsworth, Carlsmith, \& Henson, 1972). We wished to see whether E's staring would affect S's activity either immediately or during the subsequent 5-min period.

Activity was summarized in terms of mean number of counts per minute during each 5 -min period. The results are shown in the first line in Table 1. The overall change in activity over time was significant $(F=8.40, d f=2 / 36$, $\mathrm{p}<.01$ ), with a slight decrease during staring and a marked increase afterward. The decrease from Time 1 to Time 2 was not significant $(F<1.0)$; the increase from Time 1 to Time 3 was significant $(F=6.94, \mathrm{df}=1 / 18$, $p<.05)$. There was no measurable effect of sex.

\section{Experiment 2: Restriction of Movement}

Ten male and 10 female Ss were run in the setting noted in Experiment 1, except that the signal lamp in front of $\mathrm{S}$ was wired through the motion detector so that it could be made to flicker whenever $S$ moved. At the end of the first period, E activated the lamp, explained the apparatus, and instructed $S$ to keep the light off by not moving. At the end of the second period, E turned off the lamp. E faced away from $S$ during all three periods.

Restriction of movement is one aspect of crowding. Males respond more negatively to crowding than do females (Freedman, Levy, Buchanan, \& Price, 1972), and we suspected that males might react more against restriction of movement, moving more than females either during or following restriction. 
Table 1

Mean Activity Counts Per Minute

\begin{tabular}{lccc}
\hline & \multicolumn{3}{c}{ 5-Min Time Periods } \\
\cline { 2 - 4 } & $\begin{array}{c}\text { Before } \\
\text { (Time 1) }\end{array}$ & $\begin{array}{c}\text { During } \\
\text { (Time 2) }\end{array}$ & $\begin{array}{c}\text { After } \\
\text { (Time 3) }\end{array}$ \\
\hline Experiment 1: Stare & 8 & 6 & 20 \\
Experiment 2: Restriction & 10 & 3 & 18 \\
Control & 11 & 11 & 10 \\
\hline
\end{tabular}

The results are shown in the second line in Table 1. The overall changes over time were significant $(F=$ $16.65, \mathrm{df}=2 / 36, \mathrm{p}<.001)$, as were both the decrease from Time 1 to Time $2(\mathrm{~F}=14.93, \mathrm{df}=1 / 18, \mathrm{p}<.001)$ and the increase from Time 1 to Time $3(\mathrm{~F}=8.26, \mathrm{df}=$ $1 / 18 . p<.05$ ). There was no significant sex difference.

\section{Control: Movement Over Time}

Ten male and 10 female Ss were run through a time estimation procedure similar to the above, but without staring or restriction of movement. This condition was included to assess baseline changes in activity in the absence of experimental treatment. A different female $\mathrm{E}$ ran the control Ss.

The results are summarized in the third line in Table 1. There was virtually no change over time $(\mathrm{F}<1.0)$. indicating that the increased movement after staring and after restriction of movement was not due to a tendency for Ss to move more toward the end of their 15 -min period of sitting.

\section{Experiment 3: Startle}

The 20 control Ss were used to examine the startle response. At the end of the control session, E stated that there would be another part to the experiment and left the room briefly. Before leaving, she introduced our definition of a high-arousal manipulation to half the Ss (5 males and 5 females): a hypodermic syringe, alcohol, cotton. and assorted other medical paraphernalia were brought into view. After leaving the room, she switched the motion detector output into an IBM 1800 data acquisition computer, which began to record activity counts per second. After $15 \mathrm{sec}$, E pressed a button that signaled the computer and sounded a 1-sec blast on an automobile horn mounted under $S$ 's table. The computer recorded activity counts per second for an additional $15 \mathrm{sec}$ and stopped.

Activity increased significantly from $1 \mathrm{sec}$ immediately before the horn blast onset to $1 \mathrm{sec}$ immediately afterward $(\overline{\mathrm{X}}=2.4$ vs $8.8, \mathrm{~F}=33.30, \mathrm{df}=$ $1 / 16, \mathrm{p}<.001)$. The arousal manipulation had no effect. Activity counts were found to be higher with the computer than with electromechanical recording equipment, since the computer was sensitive to shorter relay closures.

\section{DISCUSSION}

The ultrasonic motion detector is simple to operate and can be used with a variety of peripheral recording devices. Of course, individual differences are great, and within-S designs should be used when possible. Correlations of individual differences in activity might be examined if large numbers of Ss are used. When Ss are being compared with one another, they should be positioned similarly vis à vis the equipment. Large groups could be studied using multiple sensors, and the directional quality of the device makes it possible to assess the activity of two interacting individuals independently of one another. The equipment can be used with human or animal Ss.

Considerable work needs to be done on the parameters of activity to which the motion detector responds, the relationship between activity and other measures of arousal, and the utility of this technique in various settings (e.g., in prisons). We are currently developing more portable equipment; the motion detector output is recorded directly on magnetic tape to be processed at a later time.

\section{REFERENCES}

Ellsworth, P. C.. Carlsmith, J. M., \& Henson, A. The stare as a stimulus to flight in human subjects: A series of field experiments. Journal of Personality \& Social Psychology, $1972,21,302-311$

Freedman, J. L.. Levy, A. S., Buchanan, R. W.. \& Price, J. Crowding and human aggressiveness. Journal of Experimental Social Psychology, 1972, 8, 528-548.

Galton, F. The measure of fidget. Nature, 1885, 32, 174-175.

Webb, E. J., Campbell, D. T., Schwartz, R, D.. \& Sechrest. L Unobtrusive measures: Nonreactive research in the social sciences. Chicago: $\mathrm{R}$ and McNally, 1966.

(Received for publication July 24, 1973: revision received September 19, 1973.) 